Research Article

\title{
Process Product Design Based on Multimode Interaction Design
}

\author{
Chuyi Liu 10 \\ Nanchang University, Nanchang, JiangXi 360100, China \\ Correspondence should be addressed to Chuyi Liu; 631418010427@mails.cqjtu.edu.cn
}

Received 9 September 2021; Revised 21 October 2021; Accepted 3 November 2021; Published 18 November 2021

Academic Editor: Rahman Ali

Copyright (c) 2021 Chuyi Liu. This is an open access article distributed under the Creative Commons Attribution License, which permits unrestricted use, distribution, and reproduction in any medium, provided the original work is properly cited.

There are many problems in the current process product design, such as poor interaction and low overall efficiency, so a process product design method based on multimode interaction design is proposed. Based on the relationship model, environment model, and object-oriented model of process product design, the process of process product development and design is analyzed. On this basis, the finite state machine is used to analyze the state of the designer to complete the task sequence, as well as the related design task planning, constructing craft products multimodal interaction mechanism, with the improved fuzzy analytic hierarchy process to evaluate the quality of the products, according to the evaluation results of technology of product design optimization. The experimental results show that both experts and ordinary users give a high evaluation of the product designed in this paper, and the design cycle of the product is significantly shortened, indicating that this method can fully save the design time and improve the overall efficiency.

\section{Introduction}

Human society has entered the information age, knowledge economy is the economic form of information society, and whether the manufacturing industry is strong or not is an important indicator to measure the economic strength of a country [1]. The rapid development of IT technology and communication technology has greatly expanded the depth and breadth of manufacturing industry and promoted the development and innovation of manufacturing technology. With the initial formation of economic globalization and integration pattern, how to make more extensive use of global resources, improve the ability to respond quickly to the market, and design excellent process products has become a key issue for relevant manufacturing enterprises to consider $[2,3]$.

In the process of product design, it is necessary to analyze the structure, material, and precision requirements of the parts of the new product to determine the manufacturability and assemblability of the product. At present, the design of craft products is carried out by craft personnel based on their personal technical experience, which is relatively poor in standardization and low in efficiency. Therefore, it is necessary to conduct multimode interaction design for process products to improve the design quality and overall efficiency of process products [4]. Product design process is crucial to satisfy customers' needs and expectations. The product design planning and decisions are made by different divisions and departments, which causes excessive cost of the process [5]. The industrial revolutions are associated with how the operations of an enterprise affect its manufacturing system and affect the value chain from product design to its marketing and disposal. It needs to be ensured that the designed product will help the company fully benefit from the industrial revolution [6]. Small- and medium-sized enterprises rely on skilled and technical workforce to increase productivity. Crowdsourcing offers the opportunity for these enterprises to get access to the online communities that provide these services. There are numerous problems with crowdsourcing that include information sharing, collaborative product design in virtual environment, design evaluation, and feedback generation [7]. The use of design innovation processes and the tools used for this are perceived by technology-driven enterprises to enable the enterprises to reframe their approach to product and business model offerings, new solutions, and innovative products. This enables the companies to rapidly test viability of the new products and business models using prototyping and end-user engagement [8]. 
According to the above analysis, this paper proposes a process product design method based on multimode interaction design, and the effectiveness of the method is verified by experiments. The key contributions of the paper include the following:

(1) We define the detailed process of product design, the environment model, and the object-oriented model of the process. The object-oriented method of design decomposes the process into the design of several parts and entities.

(2) We adopt multimode interactive way of the design process to improve the design efficiency, quality, and user experience. The multimode interaction design process is composed of the planning layer and the behavior perception layer.

(3) We define a detailed evaluation index system to ensure the quality of the process product design, which is the basis of the comprehensive evaluation of the design quality.

(4) At the end, we set up an experimental environment that consists of the product design environment and the production environment and design 10 products to evaluate the effectiveness of the approach.

\section{Process Product Design Method}

2.1. Theoretical Basis of Product Design. In essence, the process product design method based on multimode interaction design is a process with strong sequence, interaction, and iteration. Technology product design requirements through the whole process of product life cycle information sharing between the designers from the start consider all factors about the process of product design, so as to improve quality, shorten the development cycle, reduce cost and environmental protection, and so on. The purpose of comprehensive optimization is a kind of integration, parallel processing method of product design, manufacturing, and related process [9].

The process of technological product design is a process of overlapping and compression of each activity link, as shown in Figure 1.

The above process product design process not only reflects the serial characteristic of general product design but also highlights the interactive and iterative characteristic of process product design. The designer considers factors such as product technology while ensuring product performance. In the process of product design, each subprocess can be carried out sequentially, but some subprocesses are sometimes parallel, intersecting, and even repeated [10].

Process product design requires designers to consider function, manufacturing, assembly, inspection, materials, and other factors related to the process and inevitably involves maintenance, environment, sales, recycling, and other subsequent process factors, and the relationship between various factors is difficult to determine. The relationship model of process product design is shown in Figure 2.

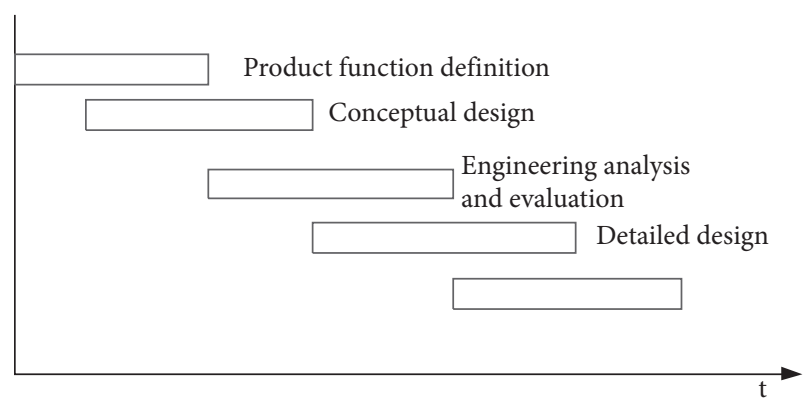

Figure 1: Product design process.

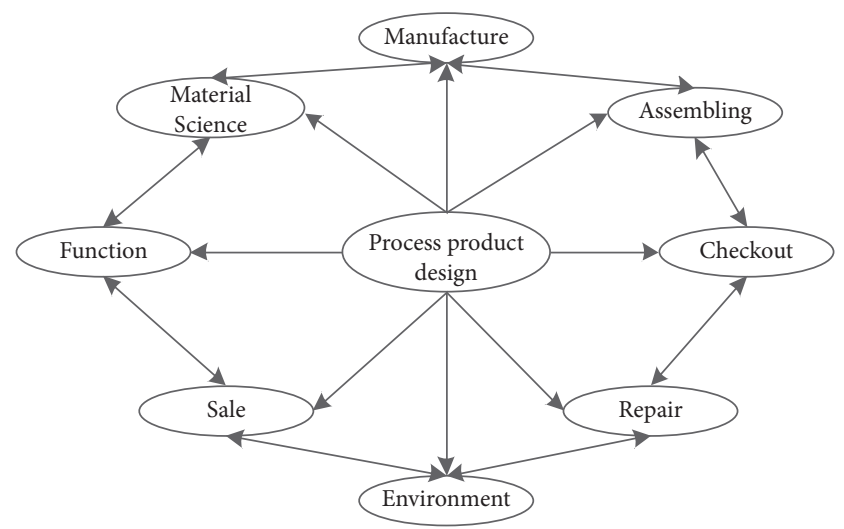

FIGURE 2: Relationship model of process product design.

Process product design is to achieve the overall optimization of product process by comprehensively considering the process factors of each manufacturer in the decentralized network production environment. Product development in the networked environment has been transformed from a single designer to multiple designers [11]. The process product designer faces a more complex environment, as shown in Figure 3.

In an independent enterprise, designers can quickly familiarize themselves with the production environment and design products with better technology according to their experience. But in the environment of the network alliance enterprise production pattern, the number of the enterprises also changes frequently; the designer cannot please everyone personally familiar with the production environment. Experience alone is not enough; this requires the designer to timely access the actual production data and design the excellent craft products [12].

According to the process product design process and object-oriented methodology, the process product design is decomposed into the design of several parts, and each part is divided into several entities according to the process factor, as shown in Figure 4.

As an important part of product development process, product design process consists of reloading, compression, and integration of each activity link, as shown in Figure 5.

The product model repository stores existing product information. Since most of the current industrial product design is conventional design, the existing data and structure of similar 


\begin{tabular}{|c|c|c|c|}
\hline \multicolumn{4}{|c|}{ Network alliance enterprise } \\
\hline \multirow{2}{*}{ Alliance leader enterprise } & \multicolumn{3}{|c|}{ Partner enterprise 1, .., Partner enterprise $\mathrm{n}$} \\
\cline { 2 - 4 } & \multicolumn{3}{|c|}{ Designer 1, .., Designer n } \\
\hline \multicolumn{4}{|c|}{ Enterprise industrial database } \\
\hline Function & Material science & Manufacture & Assembling \\
\hline Checkout & Transportation & Packing & Repair \\
\hline \multicolumn{4}{|c|}{ Process product design } \\
\hline
\end{tabular}

Figure 3: Process product design environment model.

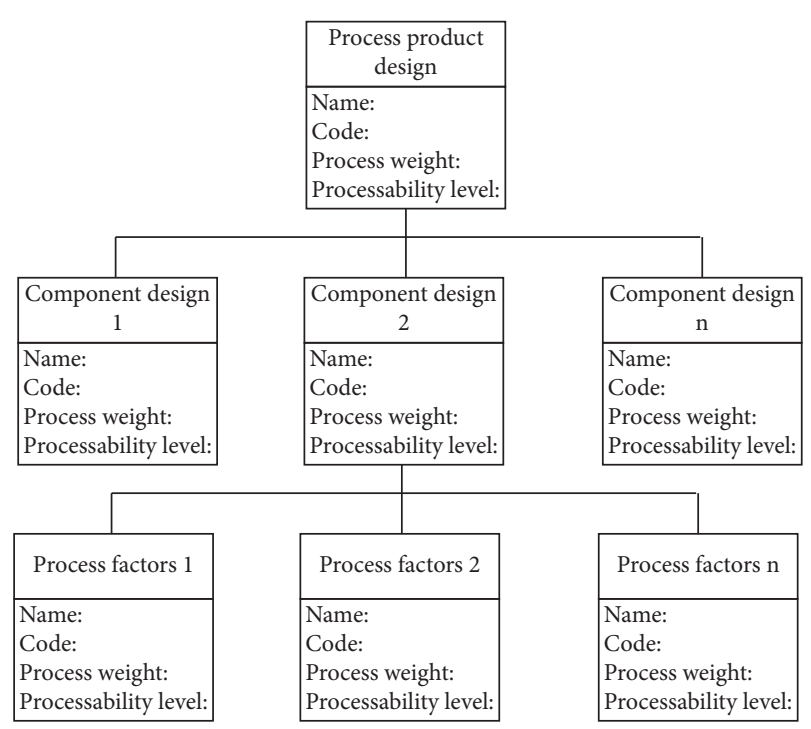

Figure 4: Object-oriented model of process product design.

products can be referenced to the current product design. Moreover, these data and structure have already passed the actual test and have better technology. With the process of product design, the content of product model library will become more and more rich, and more and more available structures will also be available $[13,14]$. Process database includes enterprise resources, various product process specifications, and process data. The basic process data can guide the product design to meet the basic process requirements, and each enterprise's existing product process reflects the production characteristics and production capacity of the enterprise and can give designers a lot of hints. Enterprise resource library is a collection of manufacturing resources of an enterprise, reflecting the production personnel, equipment, technology, management, and other aspects of each enterprise and centrally reflecting the production capacity of each enterprise [15]. Whether the production of products can be successfully completed by the existing resources, or the training of personnel, the update of equipment and the introduction of new technology can be completed, reflecting whether the overall performance of the process product is good or not.

2.2. Multimode Interaction Design of Process Products. At present, with the continuous improvement of the development level of science and technology, it is required that multimode interaction can be realized in the design process of technological products, so as to improve the design efficiency of products, product quality and user experience. Therefore, this paper carries out multimode interactive design of process products according to the design requirements of process products [16].

In order to realize distributed cooperation, the control structure and the information interaction channel between designers should be established first. The hybrid coordination structure between the designers is shown in Figure 6 .

In the process of multimode interaction design of technological products, the hybrid coordination structure is mainly composed of the planning layer and the behavior perception layer, and the results can be used to achieve indepth analysis of the relationship between tasks, designers, and behaviors [17]. Task planning includes the assignment of tasks among designers and the decomposition and refinement of each designer's respective tasks; thus generating a series of subtasks, then dividing the completion process of each subtask in detail, and using finite state machine (FSM) for designers in the process of technology products multimodal interaction design to complete the task by the state sequence were analyzed, and the related design task planning is by a series of discrete states in a certain sequence, and each state contains several basic behaviors. A collection of these behaviors described the characteristics of the current state. The transition between states is realized by the change of designer's behavior time series, so the execution process of a task can be described as a process with state as node and behavior time series as transition.

The interaction between designers can significantly promote the design level of craft products. First, it can obtain information about design tasks and other designers to make up for the lack of their own ability. Second, frequent information exchange and consultation are used to achieve close cooperation $[18,19]$.

In the process of multimode interaction design of process products, the efficiency of information interaction has obvious benefits for some specific types of tasks. In many cases, even a small amount of information interaction can play a big role. In human society, designers' cooperation mainly relies on two information media: language and observation. Therefore, this paper designs the multimode interaction mechanism of process products, as shown in Figure 7.

The characteristics of multimode interaction mechanism of process products are as follows.

2.2.1. Grouping Mechanism. The $N$ designers are divided into $K$ groups, and the number of members in the group is $m_{i}$ and $i-1,2, \ldots, k$. Designers in each group can execute tasks independently through cooperation, so there are $K$ groups of designers performing tasks in parallel. The relevant research shows that appropriate grouping can reduce the amount of data needed to be transmitted in the process of designers' interaction, simplify the coordination strategy, and effectively avoid the bottleneck of information interaction and difficult information transmission. 


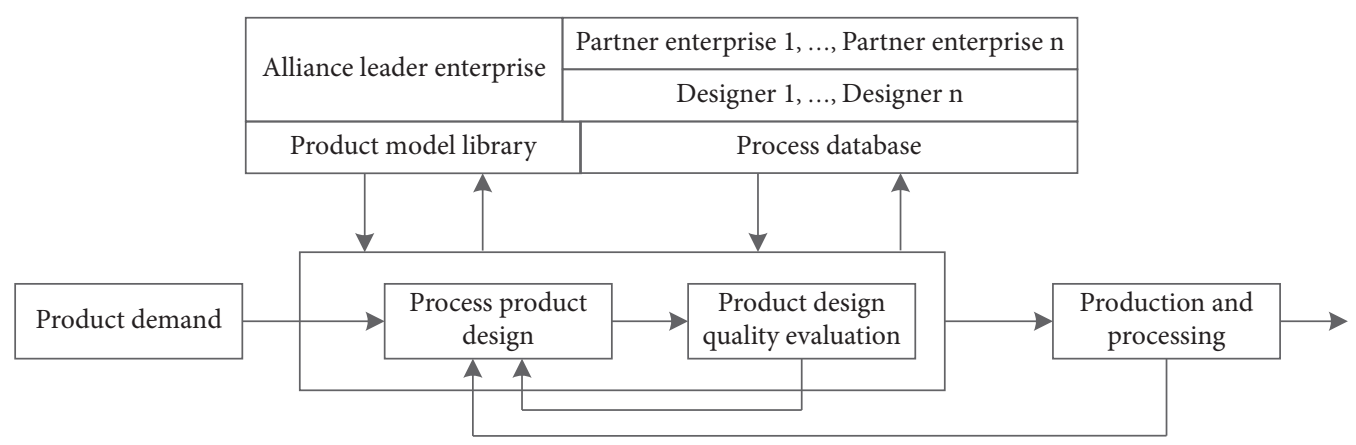

FIgURE 5: Product design and development process.

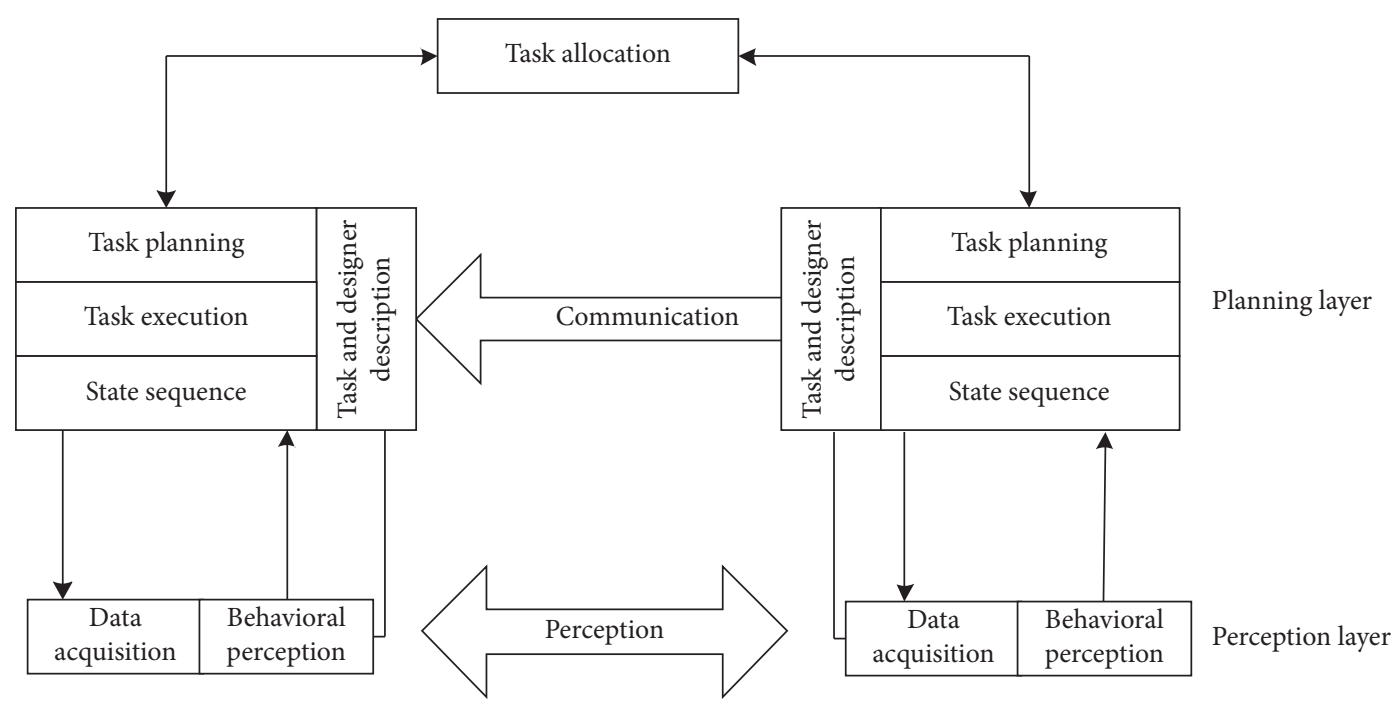

FIGURE 6: Hybrid coordination structure.

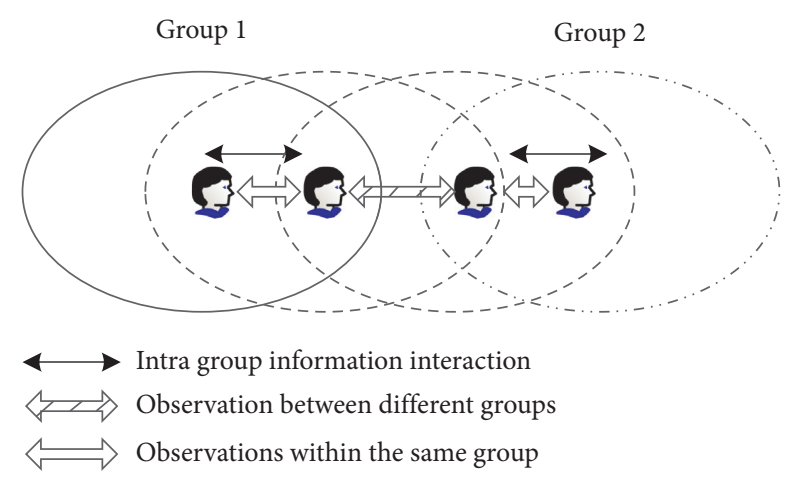

FIgURE 7: Designer interaction.

2.2.2. Explicit Information Interaction within the Group. The explicit information interaction between designers only occurs within the group, and only when each subsequent state is reached, the message flag describing the start of the current state is sent to the partner within the group once. This short messaging mechanism is based on the premise that designers know each other's internal state model. Due to the small number of designers' internal states, the amount of information interaction data between designers is very small, but the amount of information expressed is not reduced.

2.2.3. Intragroup Local Perception. Since the cooperation behaviors between designers in the group must depend on the perception results of related tasks and such perception information can effectively supplement the content of explicit information interaction, it can be said that the content of explicit information interaction is coarsely grained and the observation information is fine-grained.

2.2.4. Intergroup Local Perception. In order to realize intergroup coordination (regional division of labor, etc.), the designer's intergroup observation is also necessary.

The multimode interaction mechanism of process products has the following advantages:

(1) Information complementarity: two information interaction channels can provide information that is difficult for each other to obtain.

(2) Efficiency of information interaction: information interaction occurs at the planning level, with concise content, discrete time, and high information 
utilization rate. Under the condition of detailed task planning, more designers can be accommodative to carry out process and product tasks at the same time.

(3) Real-time: the coordination among designers based on perception can make full use of the processing ability of designers to realize fast and real-time behavior prediction and perception, thus laying a firm foundation for the good completion of subsequent process product design tasks.

(4) Reliability: the combination of the two reduces the number of communication between designers in the process of product design, reduces unnecessary time overhead, improves the coordination and efficiency in the process of product design, and can design more high-quality process products.

2.3. Process Product Design Quality Evaluation. The selection and establishment of evaluation index system are the important bases of comprehensive evaluation and the guarantee of effective evaluation of product design quality. Indicators are the parameters used to evaluate a system. For example, generally speaking, any indicator reflects and depicts one aspect of something. The most ideal method to evaluate the quality of product design is to directly test the function and performance of the product during its use, because while the use of major problems causes significant losses to the user, it also causes a bad impact on the reputation of the enterprise. Therefore, it is necessary to evaluate the quality of product design after the completion of product design. But until now, the relevant technical literature has not introduced a more perfect evaluation method of product design quality, which brings a greater randomness to the product design work, the product design quality cannot be strictly controlled. Therefore, it is of great value not only in theory but also in practice to study and put forward the evaluation criteria and evaluation system of product design quality. Based on the connotation of product design quality, the evaluation index system of product design quality is determined. Evaluation index system of process product design quality is shown in Table 1.

In the comprehensive evaluation system, the unit and magnitude of each index value are generally different. Therefore, there are differences among the indexes, which brings inconvenience to the comprehensive evaluation. In order to reflect the actual situation as much as possible, we eliminate the influence caused by the different units of each indicator and the great difference between their numerical orders of magnitude and avoid the occurrence of unreasonable phenomenon; it is necessary to carry out the dimensionless treatment of evaluation indicators. The indexes of the evaluation system are standardized, including the consistent treatment and the dimensionless treatment.

That is, according to the principle of statistics, the actual indicators are standardized and

$$
y_{i}=\frac{x_{i}-\bar{x}}{s},
$$

where $y_{i}$ is the evaluation value of the index, $x_{i}$ is the actual index value, $\bar{x}$ is the average value of the actual index value, and $s$ is the mean square error of the actual index value. The calculation formula of $\bar{x}$ is as follows:

$$
\bar{x}=\frac{1}{m} \sum_{i=1}^{m} x_{i} .
$$

The calculation formula of $s$ is as follows:

$$
s=\sqrt{\frac{1}{m} \sum_{i=1}^{m}\left(x_{i}-\bar{x}\right)^{2}}
$$

In order to reasonably determine the weight of each indicator in the index system, the following principles should be followed:

(1) The objectivity principle means that the weight of the index should fully reflect the characteristics of the evaluated object and its environment.

(2) Reflecting the intention and strategy of the evaluation subject is the principle to reflect the preference of evaluation subjects as much as possible when determining the weight of indicators.

Firstly, the importance degree of $n$ evaluation indexes about an evaluation target was compared and judged pairbypairby the scale listed in the table to obtain matrix $A$. Relative importance of evaluation indexes is shown in Table 2.

This method compares the importance of goals; if there is $n$ goal, a total of $C_{n}^{2}=n(n-2) / 2$ times. Estimate the relative importance of the $i$ th objective relative to the $j$ th objective as $a_{\mathrm{ij}}$, and approximate this to be the ratio of $w_{i} / w_{j}$ of the weight of attribute $i, w_{i}$, to attribute $j, w_{j}$. The results of paired comparison of $n$ targets are expressed by matrix $A$, and the following results can be obtained:

$$
A=\left(\begin{array}{ccccc}
a_{11} & a_{12} & a_{13} & \cdots & a_{1 n} \\
a_{21} & a_{22} & a_{23} & \cdots & a_{2 n} \\
a_{31} & a_{32} & a_{33} & \cdots & a_{3 n} \\
\vdots & \vdots & \vdots & \ddots & \vdots \\
a_{n 1} & a_{n 2} & a_{n 3} & \cdots & a_{n m}
\end{array}\right) \approx\left(\begin{array}{ccccc}
1 & \frac{w_{1}}{w_{2}} & \frac{w_{1}}{w_{3}} & \cdots & \frac{w_{1}}{w_{n}} \\
\frac{w_{2}}{w_{1}} & 1 & \frac{w_{2}}{w_{3}} & \cdots & \frac{w_{2}}{w_{n}} \\
\frac{w_{3}}{w_{1}} & \frac{w_{3}}{w_{2}} & 1 & \cdots & \frac{w_{3}}{w_{n}} \\
\vdots & \vdots & \vdots & \ddots & \vdots \\
\frac{w_{n}}{w_{1}} & \frac{w_{n}}{w_{2}} & \frac{w_{n}}{w_{3}} & \cdots & 1
\end{array}\right) .
$$

If the decision maker's estimate of $a_{\mathrm{ij}}(i, j=1,2, \ldots, n)$ is consistent, then there is 
TABLE 1: Evaluation index system of process product design quality.

Level indicators

The secondary indicators

Main and auxiliary functions of the product

The main function Auxiliary function

Man-machine safety System reliability

Compactness of construction

Material adaptability

Working durability

The structure and performance of the product

Environmental harmlessness

Artistic modelling

Design economy

Ergonomic availability Index superiority

Working stability System testability

Product performance

System controllability

Fault diagnosability

Operational agreeableness Economy of use

Structural manufacturability Part specification

Production timeliness

Tolerance rationality

Product process performance

Maintenance convenience Shipping feasibility Scrap recyclability Manufacturing economy

TABLE 2: Relative importance of evaluation indexes.

\begin{tabular}{l} 
Scale \\
\hline 1 \\
3
\end{tabular}
Indicates that the two indexes $X_{i}$ and $X_{j}$ have the same importance
7
Indicates that $X_{i}$ is significantly more important than $X_{j}$ when comparing two indexes $X_{i}$ with $X_{j}$
Represents the comparison of two indexes $X_{i}$ and $X_{j}, X_{i}$ is strongly more important than $X_{j}$
Represents the two indexes $X_{i}$ compared with $X_{j}, X_{i}$ is extremely important than $X_{j}$
The bottom
The scale value between the above two adjacent conditions

$$
a_{\mathrm{ij}}=\left\{\begin{array}{l}
\frac{1}{a_{\mathrm{ji}}} \\
a_{\mathrm{ij}} a_{\mathrm{kj}}
\end{array} .\right.
$$

Moreover, decision-makers always estimate $a_{i}=1(i,=1,2, \ldots, n)$. If the decision-maker's estimates of these values $a_{\mathrm{ij}}(i, j=1,2, \ldots, n)$ are inconsistent, then only

$$
a_{\mathrm{ij}} \approx \frac{w_{i}}{w_{j}}
$$

Therefore, in general, the value of $a_{\mathrm{ij}} w_{j}-w_{i}$ is not 0 , but we can choose a set of weights $\left\{w_{1}, w_{2}, \ldots, w_{n}\right\}$ to minimize the sum of squares of error, namely,

$$
\min \left\{z=\sum_{i=1}^{n} \sum_{i=1}^{n}\left(a_{\mathrm{ij}} w_{j}-w_{i}\right)^{2}\right\}
$$

where $\sum_{i=1}^{n} w_{i}=1, \quad w_{i}>0,(i=1,2, \ldots, n)$.

The constrained scalar optimization problem is solved by Lagrange multiplier method, and the Lagrange function is

$$
L=\sum_{n}^{n} \sum_{j=1}^{n}\left(a_{\mathrm{ij}} w_{j}-w_{i}\right)^{2}+2 \lambda\left(\sum_{i=1}^{n} w_{i}-1\right) .
$$

The above equation is differentiated against $w$ to obtain the following results:

$$
\frac{\partial L}{\partial w_{l}}=\sum_{i=1}^{n}\left(a_{\mathrm{il}} w_{i}-w_{j}\right) a_{\mathrm{il}}-\sum_{j=1}^{n}\left(a_{\mathrm{lj}} w_{j}-w_{l}\right)+\lambda=0,(l=1,2,3, \ldots, n) .
$$


The above two equations constitute $n+1$ nonhomogeneous linear equations, and $n+1$ unknowns $\lambda$ and $w_{1}, w_{2}, \ldots, w_{n}$ can obtain a unique solution, which is the calculation result of evaluation index weight.

Results of the weight of industrial product design quality evaluation index were calculated, and the improved fuzzy analytic hierarchy process was used for industrial product design quality evaluation. The first advantage of the improved fuzzy analytic hierarchy process is that the threescale method belongs to complementary scale, which is in line with people's thinking logic, and its form is relatively simple. In terms of its quality, there is no possibility of inaccurate measurement. Although the priority judgment matrix is rough, it is very easy to establish. The fuzzy consistency matrix transformed from the priority judgment matrix meets the consistency condition. The improved fuzzy analytic hierarchy process is used to evaluate the design quality of industrial products. The process is as follows.

The complementary fuzzy judgment matrices $F$ and $F=$ $\left(f_{\mathrm{ij}}\right)_{n \times m}$ are established by using the three-scale method, which is called the priority judgment matrix.

The row sum $r_{i}=\sum_{j=1}^{n} f_{i j}$ is obtained, and the fuzzy judgment matrix $F=\left(f_{\mathrm{ij}}\right)_{n \times m}$ is transformed into fuzzy consistency judgment matrix $R=\left(r_{\mathrm{ij}}\right)_{n \times m}$ by using the conversion formula $r_{\mathrm{ij}}=r_{i}-r_{j} / 2 n+0.5$.

The sorting vector is obtained by the sum row normalization method. The specific calculation formula is as follows:

$$
W^{(0)}=\left(w_{1}, w_{2}, \ldots, w_{n}\right)^{T}=\left(\frac{\sum_{j=1}^{n} r_{1 j}}{\sum_{i=1}^{m} \sum_{j=1}^{n} r_{\mathrm{ij}}}, \frac{\sum_{j=1}^{n} r_{2 j}}{\sum_{i=1}^{m} \sum_{j=1}^{n} r_{\mathrm{ij}}}, \ldots, \frac{\sum_{j=1}^{n} r_{\mathrm{nj}}}{\sum_{i=1}^{m} \sum_{j=1}^{n} r_{\mathrm{ij}}}\right)^{T} .
$$

Using the conversion formula $e_{\mathrm{ij}}=r_{\mathrm{ij}} / e_{\mathrm{ji}}$, the complementary judgment matrix $R=\left(r_{\mathrm{ij}}\right)_{n \times m}$ is changed into a reciprocal matrix $E=\left(e_{\mathrm{ij}}\right)_{n \times m}$.

Take the sorting vector $W^{(0)}$ as the iterative initial value $V_{0}$ of the eigenvalue method to further obtain the sorting vector $W^{(k)}$ with high accuracy. The specific process is as follows:

(1) Determine the input comparison matrix $E_{n \times m}$, accuracy $\varepsilon$ and maximum number of iterations $N$.

(2) Find the infinite norm $\left\|V_{0}\right\|_{\infty}$ of the initial value $V_{0}$ of the eigenvector, $\left\|V_{0}\right\|_{\infty}=\max \left\{v_{01}, v_{02}, \ldots, v_{0 n}\right\}$.

(3) The eigenvector $V_{k+1}$ is solved by iterative formula $\left\{\begin{array}{l}\bar{y}_{k}=V_{k} /\left\|V_{0}\right\|_{\infty} . \\ V_{k+1}=E \bar{y}_{k}\end{array}\right.$.

(4) If $\left|\left\|V_{k+1}\right\|_{\infty}-\left\|V_{k}\right\|_{\infty}\right|<\varepsilon,\left\|V_{k+1}\right\|_{\infty}$ is the maximum eigenvalue. Normalizing $V_{k+1}$ can obtain the following results:

$$
V=\left(\frac{v_{k+1,1}}{\sum_{i=1}^{n} v_{k+1, i}}, \frac{v_{k+1,2}}{\sum_{i=1}^{n} v_{k+1, i}}, \ldots, \frac{v_{k+1, n}}{\sum_{i=1}^{n} v_{k+1, i}}\right)^{T} .
$$

The calculation result of the above formula is the target sorting vector, and the iteration ends. Otherwise, take $V_{k}$ as the new initial value to iterate again until the maximum number of iterations $N$ is completed. The ranking vector $W^{(k)}$ obtained this time is the process product design quality evaluation result determined by the improved analytic hierarchy process. The calculation formula of $V_{k}$ is as follows:

$$
V_{k}=\frac{V_{k+1}}{\left\|V_{k+1}\right\|_{\infty}}=\left(\frac{V_{k+1,1}}{\left\|V_{k+1}\right\|_{\infty}}, \frac{V_{k+1,2}}{\left\|V_{k+1}\right\|_{\infty}}, \ldots, \frac{V_{k+1, n}}{\left\|V_{k+1}\right\|_{\infty}}\right)^{T} .
$$

According to the evaluation results, the process product design is optimized, so as to complete the research on the process product design method based on multimode interactive design.

\section{Experimental Design and Result Analysis}

3.1. Experimental Preparation. In order to verify the effectiveness of the process product design method based on multimode interactive design, experiments were carried out. This experiment takes 10 kinds of process products as the research object, uses the design method of this paper to design these 10 kinds of process products, and obtains relevant evaluation data by scoring them, respectively, by experts and users, so as to verify the practical application effect of this method. The specific experimental environment is shown in Figure 8.

After 10 products are designed by using the process product design method based on multimode interactive design, the specific results are shown in Figure 9.

Any process product design cannot let everyone who has used it be satisfied, but the product design must make the product as much as possible to meet the needs of most users. Therefore, this paper adopts various methods to obtain the specific evaluation data of experts and ordinary users on the 10 products, including the following data collection methods.

3.1.1. Questionnaire Method. According to the structure of questions and responses, questionnaires can be divided into two categories: free answers (unstructured) and selective answers (structured). The free-answer questionnaire is usually called an open questionnaire, while the latter is called a closed or fixed choice questionnaire. In the research process of this paper, the questionnaire method is mainly used to complete the preliminary basic user experience data collection work. Developing the questionnaire includes the following steps: 


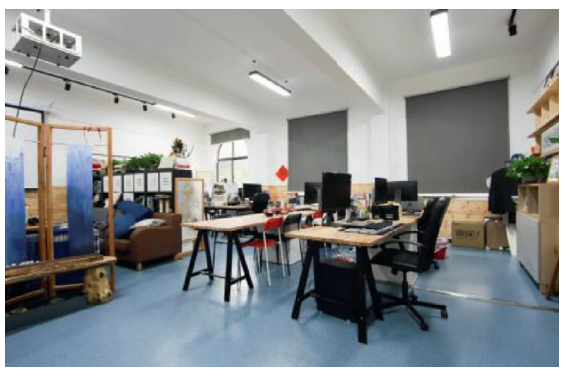

(a)

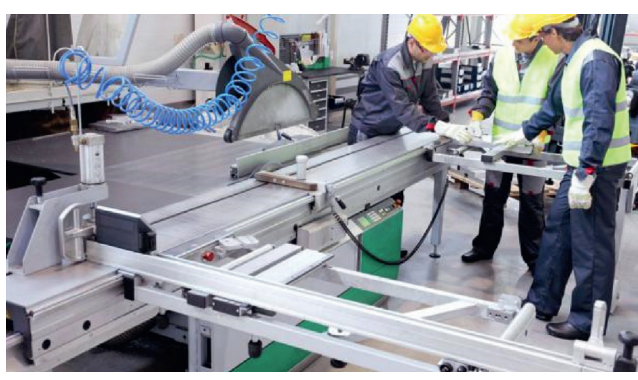

(b)

Figure 8: Experimental environment. (a) Product design and (b) production environment.

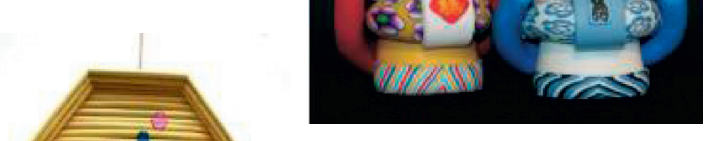

(b)

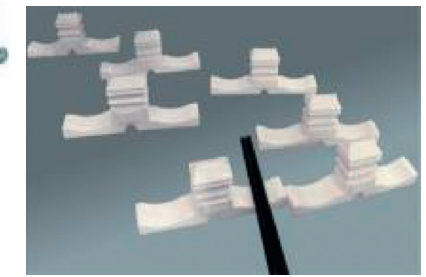

(e)

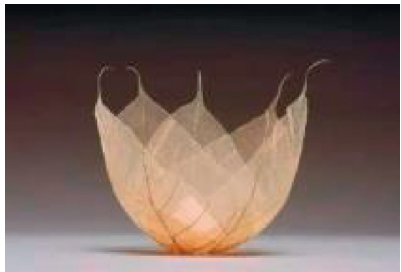

(h)

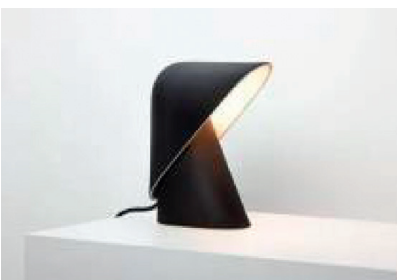

(c)

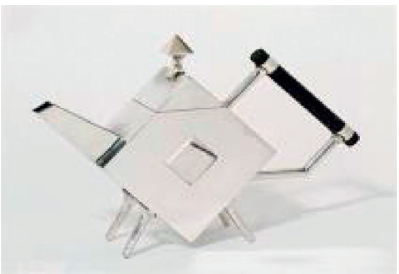

(f)

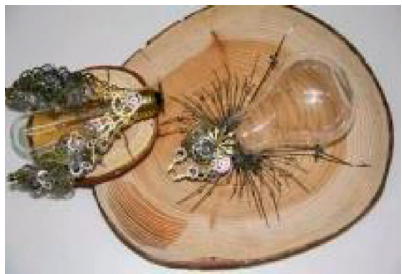

(i)

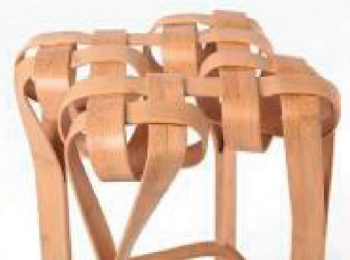

(d)

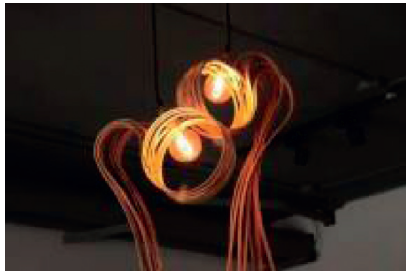

(g)

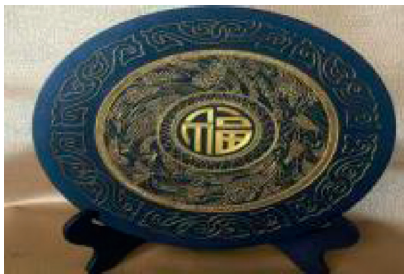

(j)

Figure 9: Process product design results based on multimode interactive design.

(1) Clarifying the purpose of research

(2) The assumption of questionnaire form

(3) Drafting a questionnaire

(4) Editing the questionnaire

(5) Compiling guidelines for questionnaire implementation

(6) Questionnaire prediction

(7) Modifying the questionnaire

(8) Developing a sample plan for questionnaire implementation

(9) Conducting investigation/data collection

(10) Analysis of data

(11) Reporting the results
3.1.2. Interview Method. Interview method is a method for analysts to collect information through face-to-face conversation with analysis objects. It is a general method for obtaining job analysis information and has good flexibility and adaptability. Interview is not only the investigation of facts, but also the consultation of opinions. It is more used for personality and individual research. The interview method is usually used in the case of a small number of respondents and is often used in combination with questionnaires and tests. The interview method is suitable for experts and scholars in related fields, such as developers, designers, and senior managers. In this study, the interview method is mainly used to collect in-depth evaluation data, so as to lay a solid foundation for the later evaluation of process product design quality satisfaction. 
3.1.3. Product Research and User Site. Product and user field studies are based on questionnaires and interviews. Product research mainly refers to the market research of the process products themselves, including the types of existing products, materials, prices, and use methods. Through product research to understand the relevant information of existing process products in the current market, it can help designers and researchers to understand the use habits of existing consumers and avoid unnecessary design ideas. This process has important guiding significance for the later design. You can find relevant information through the advantages of online resources and cooperate with the investigation of stores at the same time. The user field study is a field study of the user's use of the process product conducted by researchers entering the user's home or inviting the user to the process product use site. Its purpose is to further understand the information of the user in the real process of using the product. Specifically, designers or researchers enter users' homes, interview users, record users' process of using products, and use questionnaires to trace, so as to have a detailed understanding of the information of users' interaction with products. The detailed experience information of users using products can help designers and researchers to have a deep understanding of users' functional needs and emotional needs and use habits of products through on-site research.

3.2. Result Analysis. In this paper, industrial products are evaluated with a full score of 10 , and the average value of expert evaluation results and common user evaluation results is taken as the final evaluation result of process product design satisfaction, as shown in Table 3.

According to the analysis of data in Table 3, both experts and ordinary users gave high evaluations to the 10 process products. Experts gave 9.7 to the gprocess product, which was the highest among the 10 products, while experts gave the $h$ process product the lowest. The average user's $g$-score for craft products is 9.7, which is the highest among the 10 products. Experts give the lowest grade for the first c-type craft product. For the first $g$-type craft product evaluation, the result of the expert and ordinary user's evaluation is consistent. The evaluation results with other types of technology products have certain difference. The main reason is that experts pay more attention to the artistry of the products in the process of evaluation, while ordinary users pay more attention to the usability of the products. But generally speaking, both experts and users give a high evaluation of the products designed by using the method in this paper, which verifies the superiority of this method.

On the basis of the above experiments, the designers who adopted the method described in this paper and those who did not were divided into two groups on average, denoted as experiment group A and experiment group B. The product design cycle of the two groups was analyzed by providing the same product design requirements for the designers of the two groups. The specific comparison results are shown in Table 4.
TABLE 3: Satisfaction evaluation results.

\begin{tabular}{lcc}
\hline $\begin{array}{l}\text { Product } \\
\text { number }\end{array}$ & $\begin{array}{c}\text { Expert evaluation } \\
\text { results }\end{array}$ & $\begin{array}{c}\text { General user } \\
\text { evaluation }\end{array}$ \\
\hline$a$ & 9.5 & 9.3 \\
$b$ & 9.4 & 9.2 \\
$c$ & 9.3 & 9.0 \\
$d$ & 9.3 & 9.5 \\
$e$ & 9.5 & 9.8 \\
$f$ & 9.4 & 9.1 \\
$g$ & 9.7 & 9.7 \\
$h$ & 9.2 & 9.6 \\
$i$ & 9.3 & 9.7 \\
$j$ & 9.4 & 9.5 \\
\hline
\end{tabular}

TABle 4: Product design cycle (days).

\begin{tabular}{lcc}
\hline $\begin{array}{l}\text { Product } \\
\text { number }\end{array}$ & $\begin{array}{c}\text { The experimental group } \\
\text { A }\end{array}$ & $\begin{array}{c}\text { The experimental } \\
\text { group B }\end{array}$ \\
\hline$a$ & 15 & 25 \\
$b$ & 14 & 21 \\
$c$ & 17 & 26 \\
$d$ & 21 & 28 \\
$e$ & 18 & 32 \\
$f$ & 13 & 35 \\
$g$ & 12 & 28 \\
$h$ & 15 & 36 \\
$i$ & 16 & 27 \\
$j$ & 13 & 31 \\
\hline
\end{tabular}

By analyzing the data in Table 4, it can be seen that the design cycle of process $d$ in experimental group A is 20 days, which is the longest among the 10 products, and the design cycle of process $g$ is 12 days, which is the shortest among the 10 products. In experimental group $B$, the design cycle of the h-type product is 36 days, which is the longest among the 10 products, while the design cycle of the b-type product is 21 days, which is the shortest among the 10 products. On this basis, compared with the same type of process product design cycle, the design cycle of this method is shorter, indicating that this method can fully save the design time and improve the overall efficiency of process product design.

\section{Conclusion}

With the rapid development of market economy today, the focus of market competition has been focused on the competition of technological product quality. It has been widely accepted that the quality of craft products is first designed and then manufactured. The design quality of craft products and the interactive design method have increasingly become the focus of enterprises. In order to improve the interaction of the whole design process, this paper puts forward a process product design method based on multimode interaction design and realizes the process product design and its improvement by discussing the theoretical basis of product design, multimode interaction design of process product, quality evaluation of process product design, and so on. Experimental results show that both experts and ordinary users to products designed by this article gave a 
high evaluation, and the method, the design of the product cycle shortened obviously, shows that the method can fully save design time, improve the whole efficiency of process of product design, and fully verify the effectiveness of the method. [20].

\section{Data Availability}

The data used to support the findings of this study are available from the corresponding author upon request.

\section{Conflicts of Interest}

The author declares that he has no conflicts of interest.

\section{References}

[1] K. Takemura, S. Fukushige, and H. Kobayashi, "Proposal of product design and manufacturing processes for parts reuse using additive manufacturing," The Proceedings of Manufacturing Systems Division Conference, vol. 2020, no. 1, pp. 502-511, 2020.

[2] A. S. Macdonald, "From first concepts to Diasonograph: the role of product design in the first medical obstetric ultrasound machines in 1960s Glasgow," Ultrasound, vol. 28, no. 3, pp. 17422-17434, 2020.

[3] F. Sun and W. Shu, "Research on the innovative approach of intergrowth of $\mathrm{x}$ lacquer art in huizhou and modern product design," in E3S Web of Conferences, vol. 179, no. 5, pp. 02069-02078, EDP Sciences, HuangShan, China, 23 July 2020.

[4] S. Sugiono, A. S. Putra, R. P, A. A. Fanani, A. N. Cahyawati, and O. Oktavianty, "A new concept of product design by involving emotional factors using eeg: a case study of computer mouse design," Acta Neuropsychologica, vol. 19, no. 1, pp. 63-80, 2021.

[5] D. Tsutsumi, D. Gyulai, A. Kovács et al., "Towards joint optimization of product design, process planning and production planning in multi-product assembly," CIRP Annals, vol. 67, no. 1, pp. 441-446, 2018.

[6] M. V. P. Pessôa and J. M. J. Becker, "Smart design engineering: a literature review of the impact of the 4th industrial revolution on product design and development," Research in Engineering Design, vol. 31, no. 2, pp. 175-195, 2020.

[7] X.-J. Niu, S.-F. Qin, J. Vines, R. Wong, and H. Lu, "Key crowdsourcing technologies for product design and development," International Journal of Automation and Computing, vol. 16, no. 1, pp. 1-15, 2019.

[8] S. T. Bryant, K. Straker, and C. Wrigley, "The rapid product design and development of a viable nanotechnology energy storage product," Journal of Cleaner Production, vol. 244, Article ID 118725, 2020.

[9] N. Althuizen and B. Chen, "Crowdsourcing ideas using product prototypes: the joint effect of prototype enhancement and the product design goal on idea novelty," Management Science, vol. 15, no. 10, pp. 1-10, 2021.

[10] W. Chen, "Research on the training mode of product design talents based on the mode of sino foreign cooperation in running schools[J]," Advances in Higher Education, vol. 4, no. 10, pp. 2881-2893, 2020.

[11] R. Ginting, A. Ishak, W. Pratiwi, and R. H. Tambunan, "Designing file organizer product design using the quality function deployment method (QFD)," IOP Conference Series:
Materials Science and Engineering, vol. 1003, no. 1, pp. 012024-012031, 2020.

[12] R. Raffaeli, J. Lettori, J. Schmidt, M. Peruzzini, and M. Pellicciari, "A systematic approach for evaluating the adoption of additive manufacturing in the product design process," Applied Sciences, vol. 11, no. 3, pp. 1210-1223, 2021.

[13] X. Tan, M. Li, C. Zhang, and P. Liu, "Based on the IH derivative product design and network promotion promotion of t group," Journal of Physics: Conference Series, vol. 1744, no. 4, pp. 042215-042210, 2021.

[14] D. Moreno Nieto, M. Alonso-García, M.-A. Pardo-Vicente, and L. Rodríguez-Parada, "Product design by additive manufacturing for water environments: study of degradation and absorption behavior of PLA and PETG," Polymers, vol. 13, no. 7, pp. 1036-1048, 2021.

[15] W. Hashim, E. Mkpojiogu, A. Hussain, S. Nizam, and A. Aziz, "A product pain-pleasure framework for software product design in the usability and user experience domains," Webology, vol. 18, no. 2, pp. 1-31, 2021.

[16] L. Ren and Y. Wu, "A study on the influence of creativity of medical product design and project socialization on the success of industrial fundraising," Revista de Cercetare şi Intervenţie Socială, vol. 73, no. 1, pp. 338-349, 2021.

[17] X. Bai, O. Huerta, E. Unver, J. Allen, and J. E. Clayton, “A parametric product design framework for the development of mass customized head/face (eyewear) products," Applied Sciences, vol. 11, no. 12, pp. 5382-5396, 2021.

[18] H. Rujito, M. M. D. Utami, H. Y. Riskiawan, D. Hermanuadi, and N. Retnowati, "Product design of kolang kaling grass jelly drink through the application of quality function deployment method (case study in meru betiri national park, banyuwangi district)," IOP Conference Series: Earth and Environmental Science, vol. 411, no. 1, pp. 012024-012029, 2020.

[19] Z. Wang, S. Zhang, L. Qiu, Y. Gu, and H. Zhou, “A lowcarbon-orient product design schemes MCDM method hybridizing interval hesitant fuzzy set entropy theory and coupling network analysis," Soft Computing, vol. 24, no. 7, pp. 5389-5408, 2020.

[20] A. Abdullatif, "Alternative assessment approaches and quality product design within web-based learning environments," International Journal of Web-Based Learning and Teaching Technologies, vol. 15, no. 3, pp. 1-12, 2020. 